* Doutor em Direito pela Pontifícia Universidade Católica do Rio Grande do Sul (PUC -RS). Mestre em Direito pela Universidade Federal do Rio Grande do Sul (UFRGS). Professor do Programa de Pós-Graduação em Direito e da Faculdade de Direito da Universidade do Vale do Rio dos Sinos (UNISINOS). E-mail: rodrigo.coimbra@ terra.com.br.

** Mestranda em Direito Público, Linha de Pesquisa Novos Direitos, Sociedade e Transnacionalização, pela Universidade do Vale do Rio dos Sinos (UNISINOS). Pós-Graduada em Direito e Processo do Trabalho pela Universidade Regional Integrada do Alto Uruguai e das Missões (URI SANTO ÂNGELO).E-mail: ellarav@ hotmail.com.

\section{A LIVRE CIRCULAÇÃO DE TRABALHADORES E A NÃO DISCRIMINAÇÃO AO MIGRANTE NA UNIÃO EUROPEIA: DIGRESSÕES ACERCA DA FRATERNIDADE E DO RECONHECIMENTO NAS RELAÇÕES DE TRABALHO}

\author{
THE FREE MOVEMENT OF WORKERS AND THE \\ NON-DISCRIMINATION OF MIGRANTS IN THE \\ EUROPEAN UNION - DIGRESSIONS ABOUT \\ FRATERNITY AND RECOGNITION IN LABOR \\ RELATIONS \\ * Rodrigo Coimbra \\ **Ellara Valentini Wittckind
}

Resumo: A livre circulação de trabalhadores é uma das liberdades instituídas pela União Europeia em seus Tratados e defendida pelas suas instituições, jurídicas e administrativas. Um dos diferenciais desse Direito é que sua produção não é realizada por imposição Estatal como tradicionalmente ocorre com as normas jurídicas. Nesse contexto, é importante esta abordagem a respeito da liberdade de circulação de trabalhadores e da não discriminação ao trabalhador migrante, na União Europeia, normas aplicáveis e decisões do Tribunal de Justiça, a fim de se verificar de que forma a fraternidade e o reconhecimento contribuem para a efetivação desses direitos, conforme estudos de Habermas, Honneth e outros.

Palavras-chave: Liberdade de circulação; trabalhadores; União Europeia; não-discriminação; reconhecimento; fraternidade.

Abstract: The free movement of workers is a freedom established by the European Union in its various treaties and it's upheld by the legal and administrative institutions of said Union. One of the differentials of this right is that its creation is not carried out by State enforcement, as traditionally occurs with laws. Therefore, the approach regarding the free movement of workers and the non-discrimination of migrant workers in the European Union is extremely important because of its impact in decisions of Court and laws which, in order to verify how fraternity and recognition contribute to the realization of those aforementioned rights. We base this paper on studies of 
Habermas, Honneth and others.

Keywords: Free movement; workers; European Union; nondiscrimination; recognition; fraternity.

Como citar: COIMBRA, Rodrigo; WITTCKIND, Ellara Valentini. A livre circulação de trabalhadores e a não discriminação ao migrante na União Europeia: digressões acerca da fraternidade e do reconhecimento nas relações de trabalho. Scientia Iuris, Londrina, v. 20, n. 1, p. 194-219, abr. 2016. DOI: $10.5433 / 2178-8189.2016 v 20 n 1 p 194$. ISSN: $2178-8189$. 


\section{INTRODUÇÃO}

O presente artigo visa a analisar a livre circulação de trabalhadores na União Europeia e o problema da discriminação do trabalhador estrangeiro nos países do Bloco.

A presente investigação se justifica em razão da curiosidade despertada quando do estudo da liberdade de circulação de trabalhadores na União Europeia, considerando os estudos de Habermas (1992) e Honneth (2003) a respeito da fraternidade e do reconhecimento, aqui voltadas ao estrangeiro.

O problema que se propõe é verificar se há, porque existe e de que forma pode ser mitigada a discriminação ao trabalhador migrante, na União Europeia, especialmente quando se vive cada vez mais intensamente num processo de globalização, onde a multiculturalidade mostra-se tão presente, mesmo dentro de um só país, ou na perspectiva de uma comunidade de nações.

O ponto de partida é o estudo da legislação da União Europeia, no que tange à proteção ao trabalhador migrante contra a discriminação, passando por apresentação de casos práticos da jurisprudência dos Tribunais da União Europeia, e também realizar uma abordagem doutrinária a respeito da livre circulação de trabalhadores e filosófica no que tange à discriminação.

O método utilizado é o bibliográfico, a partir de doutrina a respeito do Direito do Trabalho da União Europeia, citação e análise de dispositivos de Tratados e outros atos e de decisões dos Tribunais da União Europeia, exposição de dados estatísticos a respeito das migrações, assim como de abordagem filosófica a respeito da discriminação do trabalhador migrante, com base em Habermas, Honneth e outros autores importantes nos cenários brasileiro e mundial.

\section{A LIVRE CIRCULAÇÃO DE TRABALHADORES NA UNIÃO EUROPEIA E A NÃO DISCRIMINAÇÃO OS TRATADOS E OUTROS ATOS E A ATUAÇÃO DOS TRIBUNAIS A ESSE RESPEITO}

No presente tópico, será analisado o direito à livre circulação, especificamente a de trabalhadores, pela abordagem dos Tratados e outros atos legislativos, a fim de se estabelecer o estudo da discriminação dos trabalhadores migrantes na União Europeia, não somente pela análise teórica, mas também pela apresentação de números e dados estatísticos de órgãos oficiais. 
Conforme Caio Mesquita Barros, se considerados os aspectos políticos, econômicos e sociais mais relevantes, cinco são as liberdades a serem alcançadas pelo processo de integração: 1) livre circulação de bens, o que pressupõe ausência de barreira alfandegária; 2) livre circulação de capital, determinando a utilização de moeda única para evitar perdas com câmbio; 3) liberdade de concorrência, havendo regras de mercado comuns para todos; 4) liberdade de estabelecimento, ou seja, o produtor estabelecer-se-á onde entender que for melhor para sua produção, e 5) a livre circulação de pessoas e de trabalhadores, a fim de que não existam mais fronteiras para os indivíduos, dentro da comunidade, seja para viver, estudar ou trabalhar. (BARROS, 2000)

Para o presente estudo, importa a livre circulação de trabalhadores, sendo que, de início, há de se demonstrar que a referência a esta liberdade não decorre única e exclusivamente do mercado, ou seja, não se tem na livre circulação de trabalhadores somente o intuito de crescimento econômico do Bloco, mas de união das pessoas, de esforços, de experiências, para que nelas cresça o sentimento de comunidade e de integração. (BARROS, 2000)

Segundo informações do sítio eletrônico da Organização Internacional do Trabalho - OIT, a livre circulação de trabalhadores facilita o desenvolvimento de novos mercados, a criação de laços comerciais (entre países de origem e de destino), a transferência de tecnologia e as reformas econômicas e políticas nos países de origem. Acrescenta-se a isto o fato de que a livre circulação de pessoas fortalece a integração também sob o ponto de vista subjetivo-cultural, através da troca de experiências de vida entre os estrangeiros e os nacionais. (OIT, 2014)

Conforme informação do sítio eletrônico da Organização Internacional do Trabalho, em 2005, cerca de 191 milhões de pessoas saíram de seus países de origem para residir e trabalhar em outros, no mundo todo. Cerca de $90 \%$ destes 191 milhões eram de trabalhadores e suas famílias (OIT, 2014). Os números são expressivos se comparados com a população brasileira que, em 2005, alcançava cerca de 172 milhões. (IBGE, 2005)

Em 2009, em meio a uma crise econômica internacional, a migração foi determinante para tensões entre estrangeiros e nacionais, na União Europeia. Isto se deu nas regiões mais afetadas pela crise, como Espanha e Irlanda, onde foi registrado aumento das hostilidades entre migrantes e trabalhadores locais, inconformados com a perda de vagas para a mão-de-obra estrangeira. Naquela época, ocorreu uma série de manifestações na Grã-Bretanha, chamando-se a atenção para o papel da crise no aumento da xenofobia. $\mathrm{O}$ maior dos protestos 
ocorreu na refinaria de petróleo de Lindsey, do grupo francês Total, que contratou 200 operários italianos e portugueses e, em resposta, os trabalhadores da companhia entraram em greve, reivindicando que as vagas fossem entregues a britânicos. (CAMPANA, 2009)

Segundo dados do "Eurostat", no final de 2012, 2,8 \% dos cidadãos da União Europeia (14,1 milhões de pessoas) residiam num Estado membro diferente do de nascimento. (EUROSTAT, 2012) De acordo com um estudo do "Eurobarômetro" de 2010, 10\% dos entrevistados informaram ter vivido e trabalhado em outro país da União, no passado. E, $17 \%$ pretendiam fruir do direito à livre circulação, na União Europeia, no futuro. (EUROBAROMETER, 2010)

Assim, devido à expressiva circulação de pessoas que se desenha, mesmo permeada por momentos de menor fluxo, a migração internacional está hoje essencialmente ligada ao tema do trabalho digno e às questões do mercado de trabalho: de garantias, de igualdade de salário, de acesso ao emprego, de manutenção do emprego, de previdência privada, dentre outras. (BARROS, 2000)

Veja-se que a política social da União Europeia pauta-se na melhoria das condições de vida e trabalho dos trabalhadores, através do progresso econômico, como referido acima, e se observa do texto do artigo 151 (antes artigo 136) do Tratado da Comunidade Europeia:

Artigo 151.o (ex-artigo 136.o TCE) - A União e os EstadosMembros, tendo presentes os direitos sociais fundamentais, tal como os enunciam a Carta Social Europeia, assinada em Turim, em 18 de Outubro de 1961 e a Carta Comunitária dos Direitos Sociais Fundamentais dos Trabalhadores, de 1989, terão por objectivos a promoção do emprego, a melhoria das condições de vida e de trabalho, de modo a permitir a sua harmonização, assegurando simultaneamente essa melhoria, uma protecção social adequada, o diálogo entre parceiros sociais, o desenvolvimento dos recursos humanos, tendo em vista um nível de emprego elevado e duradouro, e a luta contra as exclusões. Para o efeito, a União e os EstadosMembros desenvolverão acções que tenham em conta a diversidade das práticas nacionais, em especial no domínio das relações contratuais, e a necessidade de manter a capacidade 
concorrencial da economia da União. A União e os EstadosMembros consideram que esse desenvolvimento decorrerá não apenas do funcionamento do mercado interno, que favorecerá a harmonização dos sistemas sociais, mas igualmente dos processos previstos nos Tratados e da aproximação das disposições legislativas, regulamentares e administrativas. [sic] [grifou-se] (UNIÃO EUROPEIA, 2014, p. 126)

E do rol de motivos da referida Diretiva 38/2004/EC extrai-se:

Union citizenship should be the fundamental status of nationals of the Member States when they exercise their right of free movement and residence. It is therefore necessary to codify and review the existing Community instruments dealing separately with workers, self-employed persons, as well as students and other inactive persons in order to simplify and strengthen the right of free movement and residence of all Union citizens. (UNIÃO EUROPEIA, 2014, p. 1).

Um dos mecanismos práticos para por em efetividade esta Diretiva é a Rede EURES (Serviço de Emprego Europeus). A EURES é uma rede de cooperação entre a Comissão Europeia e os Serviços Públicos de Emprego dos Estados-membros, que tem por objetivo unificar as ofertas de emprego num único portal, na internet, a fim de que qualquer cidadão da União Europeia possa buscar vagas e candidatar-se a elas, em pé de igualdade com os demais concorrentes, pelo menos no que tange ao acesso à oferta de emprego. (EURES, 2015).

Importante, ainda, que se reflita acerca da liberdade de circulação de trabalhadores juntamente com sua família, o que determina o direito de residência, sem o qual a liberdade em questão não teria sentido. Inicialmente, todo cidadão da União Europeia tem direito a buscar emprego em qualquer dos Estados-membros. Para esta finalidade, pode permanecer no país em questão, enquanto perdurar a procura. Encontrando, tem direito de residir por período

\footnotetext{
1 Directive 2004/38/EC: Article 16 - General rule for Union citizens and their family members 1 . Union citizens who have resided legally for a continuous period of five years in the host Member State shall have the right of permanent residence there. This right shall not be subject to the conditions provided for in Chapter III.
} 
certo, ou indeterminadamente ${ }^{1}$, com sua família, aqui se entendendo o cônjuge e aqueles que dependam financeiramente do trabalhador migrante (ascendentes, ascendentes do cônjuge e filhos menores), conforme Diretiva 38/2004/EC.

Não obstante este cenário de proteção, as dificuldades existem, como nos casos de trabalhadores informais, de pessoas com qualificação, porém, habilitados em Cursos não reconhecidos pelo país de recepção. Tanto é assim que na $103^{\text {a }}$ Convenção da OIT, realizada em 28 de maio de 2014, em Genebra, o diretor-geral da Organização avaliou a questão das migrações no mundo, e embora em escala menor no âmbito da União Europeia, se pode citar a preocupação da entidade em relação ao fenômeno:

Diante desse panorama, é de grande importância desenhar políticas de migração que primeiramente facilitem a circulação dos trabalhadores e respondam ao desequilíbrio que existe atualmente entre a distribuição de oportunidades de trabalho e a distribuição da população em idade de trabalhar. (OIT, 2014, p. 1).

$\mathrm{Na}$ Carta dos Direitos Fundamentais da Europa, no artigo 15, tratou-se da "Liberdade profissional e direito de trabalhar", sendo que todos os cidadãos têm direito de procurar emprego e se estabelecer em qualquer Estado Membro. E, no artigo 21, a Carta trata do princípio da não discriminação em razão de "sexo, raça, cor ou origem étnica ou social, características genéticas, língua, religião ou convicções, opiniões políticas ou outras, pertença a uma minoria nacional, riqueza, nascimento, deficiência, idade ou orientação sexual", sendo também "proibida toda a discriminação em razão da nacionalidade". (UNIÃO EUROPEIA, 2014, p. 13).

Na referida Carta também se encontra disposição a respeito da não discriminação (artigo 21) ${ }^{2}$. O Tratado de Lisboa, modificando o Tratado da União Europeia, em seu artigo $1^{\circ}$-A, institui que:

A União funda-se nos valores do respeito pela dignidade

\footnotetext{
Artigo 21.o Não discriminação 1. É proibida a discriminação em razão designadamente, do sexo, raça, cor ou origem étnica, social, características genéticas, língua, religião ou convicções, opiniões políticas ou outras, pertença a uma minoria nacional, riqueza, nascimento, deficiência, idade ou orientação sexual. 2 . No âmbito de aplicação do Tratado que institui a Comunidade Europeia e do Tratado da União Europeia, e sem prejuízo das disposições especiais destes Tratados, é proibida toda a discriminação em razão da nacionalidade.
} 
humana, da liberdade, da democracia, da igualdade, do Estado de Direito e do respeito pelos direitos do Homem, incluindo os direitos das pessoas pertencentes a minorias. Estes valores são comuns aos Estados-Membros, numa sociedade caracterizada pelo pluralismo, a não discriminação, a tolerância, a justiça, a solidariedade e a igualdade entre homens e mulheres. (UNIÃO EUROPEIA, 2014, p. 5).

Na mesma linha, no rol de motivos da Diretiva 38/2004/EC, extrai-se que a cidadania da União deverá ser o estatuto fundamental dos nacionais dos Estados-Membros quando exercerem o seu direito de livre circulação e residência. É, pois, necessário codificar e rever os instrumentos comunitários em vigor que tratam separadamente dos trabalhadores, dos trabalhadores autônomos, bem como dos estudantes e pessoas inativas, a fim de simplificar e reforçar o direito de livre circulação e residência de todos os cidadãos da União ${ }^{3}$.

A Organização Internacional do Trabalho (OIT) é o órgão que mais se destaca em ações para a defesa dos direitos dos trabalhadores e de suas famílias. Criada pela ONU, em 1919, a OIT vem atuando em duas frentes: na elaboração de convenções e recomendações que estabelecem modelos a serem seguidos pelas legislações dos países signatários e nos projetos de cooperação técnica, através dos quais atua juntamente com o Estado signatário para o desenvolvimento de ações práticas de combate à discriminação, à desigualdade, a condições de trabalho inadequadas, dentre outros ${ }^{4}$.

No âmbito da OIT, dentre os instrumentos celebrados se destacam a Convenção sobre a Migração para o Trabalho de 1949 (n 97), baseada na

\footnotetext{
3 Diretiva 38/2004/EC. Union citizenship should be the fundamental status of nationals of the Member States when they exercise their right of free movement and residence. It is therefore necessary to codify and review the existing Community instruments dealing separately with workers, self-employed persons, as well as students and other inactive persons in order to simplify and strengthen the right of free movement and residence of all Union citizens.

${ }^{4}$ Exemplo disso foi o relatório da oficina do Projeto 'Monitorando e Avaliando o Progresso no Trabalho Decente' (MAP) - OIT/CE. OIT BRASIL. Disponível em: <http://www.oitbrasil.org.br/sites/default/files/ topic/decent work/pub/oficina de consulta 300.pdf $>$. Acesso em 25, jan./2015. Vide também: LAVINAS, Lena et al. 1998. Trabalho a domicílio: novas formas de contratualidade. Projeto Inter-regional OIT/Danida (Organização Internacional do Trabalho/ Organização Dinamarquesa para o Desenvolvimento) "Trabalho a domicílio na economia global". Relatório de Pesquisa preparado para a Consulta técnica preliminar sobre trabalho a domicílio na América Latina. Santiago, Chile: OIT; e A OIT no Brasil - Trabalho decente para uma vida digna. OIT - Organização Internacional do Trabalho. Disponível em: $<$ http://www.justica.sp.gov. $\mathrm{br} /$ StaticFiles/SJDC/ArquivosComuns/ProgramasProjetos/NETP/Relat $\% \mathrm{C} 3 \%$ B3rio.\%20OIT\%20no\%20 Brasil.pdf $>$. Acesso em 25, jan./2015.
} 
igualdade de tratamento de nacionais e imigrantes legais em matéria laboral e a Convenção sobre os Trabalhadores Migrantes de 1975 ( $\left.\mathrm{n}^{\circ} 143\right)$ que visa a eliminar a migração e o emprego ilegais e estabelece condições quanto ao respeito dos direitos dos migrantes ilegais, estabelecendo, simultaneamente, medidas com o objetivo de eliminar os movimentos migratórios clandestinos e de penalizar os empregadores de imigrantes ilegais. (OIT, 2014)

A Convenção $\mathrm{n}^{\circ} 143$ da OIT relativa às Migrações em Condições Abusivas e à Promoção da Igualdade de Oportunidades e de Tratamento dos Trabalhadores Migrantes já dispunha, no seu artigo 10 que:

[...] os membros para os quais a presente Convenção esteja em vigor comprometem-se a formular e a aplicar uma política nacional que se proponha promover e garantir, por métodos adaptados às circunstâncias e aos costumes nacionais, a igualdade de oportunidades e de tratamento em matéria de emprego e de profissão, de segurança social, de direitos sindicais e culturais e de liberdades individuais e coletivas para aqueles que se encontram legalmente nos seus territórios na qualidade de emigrantes ou de familiares destes. (OIT, 2014, p. 5).

A Convenção Internacional sobre a Proteção dos Direitos de Todos os Trabalhadores Migrantes e dos Membros das suas Famílias, adotada pela Resolução 45/158 da Assembleia Geral da ONU, em 18/12/1998, estabelece que os Estados devem respeitar os direitos humanos fundamentais de todos os trabalhadores migrantes. Os Estados devem suprimir as migrações clandestinas e o emprego ilegal de mão-de-obra migrante. Igualmente, devem adotar políticas que garantam a igualdade de tratamento em matéria de emprego e de profissão, de segurança social, e de direitos sindicais e culturais. A Convenção também obriga aos Estados que a ratificarem a conceder, sem discriminação alguma com base na nacionalidade, raça, religião ou sexo, aos trabalhadores migrantes, que se encontrem legalmente no seu território, tratamento igual àquele de que beneficiam os seus nacionais, em matéria de legislação laboral. (OHCHR, 2015)

O artigo 25 da Convenção Internacional sobre a Proteção dos Direitos de Todos os Trabalhadores Migrantes e dos Membros das suas Famílias estabelece que "os trabalhadores migrantes devem beneficiar de um tratamento não menos favorável que aquele que é concedido aos nacionais do Estado de emprego em 
matéria de retribuição" e outras condições de trabalho e de emprego. A alínea 3 do mesmo artigo impõe aos Estados a adoção de todas as medidas adequadas a garantir que os trabalhadores migrantes não sejam privados desses direitos. O instrumento, considerado uma das 9 convenções fundamentais sobre direitos humanos, conta com 31 signatários e 42 ratificações. (OHCHR, 2015)

Nesse norte, importante ressaltar que a Convenção 111 da OIT, de 1958, foi o primeiro instrumento internacional que se ocupou de tratar a respeito da não discriminação em matéria de emprego. Na redação do documento se definiu a discriminação como distinção negativa através da qual se priva alguém da igualdade de oportunidade ou de tratamento no trabalho. $\mathrm{O}$ artigo primeiro a definiu como:"toda distinção, exclusão ou preferência fundada na raça, cor, sexo, religião, opinião política, ascendência nacional ou origem social, que tenha por efeito destruir ou alterar a igualdade de oportunidade ou de tratamento em matéria de emprego ou profissão;" e "qualquer outra distinção, exclusão ou preferência que poderá ser especificada pelo Membro interessado depois de consultadas as organizações representativas de empregadores e trabalhadores". (OIT, 2014, p. 1). Conclui-se que o rol de critérios de não-discriminação não é taxativo, podendo a eles serem acrescentados, por exemplo, idade e condições físico-mentais (em defesa dos idosos e das pessoas portadoras de deficiências).

Ocorre que, mesmo diante dos direitos formalmente garantidos, conforme a $8^{a}$ Conferência Ministerial do Conselho Europeu, ocorrida em 2008, a discriminação ainda mantém e justifica "estratificação e segmentação no mercado de trabalho", além de contribuir para a manutenção e reforço de atitudes que relegam ou restringem a certos grupos o acesso ao trabalho.

$\mathrm{Na}$ linha de Shelton, embora os textos de direitos humanos reconhecem que "todas as pessoas" têm direitos, é fato que embora as leis sejam aparentemente neutras, podem trazer discriminações quando de sua aplicação, pois pode impedir que algumas pessoas não possam exercer certos direitos ${ }^{5}$. Isto porque "hay factores estructurales que pueden dejar a ciertos grupos a la zaga en relación con el resto de la sociedad, independientemente de que formalmente reciban un trato equitativo o exista una prohibición de discriminación directa". (SHELTON, 2014, p. 13-15)

A par destas informações iniciais, há de se ponderar que o princípio da

\footnotetext{
${ }^{5} \mathrm{~A}$ autora refere como exemplo o direito de acesso à justiça que pode não ser efetivo quando se exige o pagamento de custas e a contratação de advogados para que as pessoas venham a exercê-lo.
} 
não discriminação dos trabalhadores em razão de sua nacionalidade deve ser analisado sob o enfoque de um direito humano fundamental, porquanto:

(...) em geral pode assinalar-se que a proibição de discriminar constitui um dos direitos fundamentais mais sólidos de qualquer sistema de proteção de direitos humanos ou fundamentais, seja interno ou internacional. Isto é assim porque não é concebível um ordenamento jurídico medianamente evoluído no qual se consagre a discriminação racial ou segregação, a discriminação religiosa, ou política etc; se se produz uma situação de tal caráter, estaremos diante de algo muito distinto de um Estado de Direito (SANCHO, 1989, p. 147).

Palomeque López e De La Rosa (2001) entendem que a não discriminação abrange: igualdade e não discriminação no emprego e nas condições de trabalho. Quanto à primeira, o trabalhador estrangeiro tem direito de competir igualitariamente com o nacional, pelo emprego. Quanto à segunda, os nacionais e estrangeiros têm direito às mesmas condições de trabalho, no que tange à organização do trabalho, ao acesso à assistência e à previdência, à sindicalização, à igualdade de remuneração, à despedida não discriminatória, entre outros. (PALOMEQUE LÓPEZ; DE LA ROSA, 2001)

Melgar et. al. ressaltam que a liberdade de circulação de trabalhadores constitui um aspecto importante para a não discriminação na esfera das relações de trabalho, pois determina a abolição de qualquer tratamento diferenciado com base na nacionalidade entre os trabalhadores dos Estados-membros. (MELGAR; MORENO; NAVARRO, 1998)

A fim de que o trabalhador migrante possa efetivamente por em prática a liberdade de trabalhar em qualquer Estado-membro da União Europeia, a ele é garantido o acesso ao trabalho, através da possibilidade de obter emprego pelos mesmos meios que os nacionais, isto é, não poderá haver discriminação na oferta, tampouco na seleção de emprego. (MELGAR; MORENO; NAVARRO 1998)

Sobre essa questão, Pocar (1998) enfatiza acerca da vedação de qualquer discriminação por parte do Estado-membro em relação aos trabalhadores migrantes, como referido. Ainda, informa quanto à obrigação de o Estado-membro dar preferência aos trabalhadores da União Europeia, a 
terceiros, advindos de outros países (segundo o autor, esta conclusão emerge, implicitamente, dos termos do artigo 2 do Regulamento $n^{\circ}$ 1.612/68). (POCAR, 1988)

A participação dos Tribunais da União Europeia para a garantia da livre circulação de trabalhadores é ativa, pois inúmeras são as decisões e recomendações expressas pelos mesmos, quanto à questão. No sítio eletrônico da União Europeia, na sessão da jurisprudência dos Tribunais, foram encontradas várias decisões a respeito desses direitos, dentre as quais se colacionam as seguintes, sendo aqui citados trechos de suas fundamentações, todos oriundos do Tribunal de Justiça da União Europeia:

76. Em matéria de livre circulação de trabalhadores, o Tribunal de Justiça considerou que, "[s]e é certo que os direitos de livre circulação previstos [no artigo $45 .^{\circ}$ TFUE] beneficiam os trabalhadores [...], nada na letra do referido artigo indica que estes direitos não possam ser invocados por outrem" (29). Por conseguinte, o Tribunal de Justiça declarou que "o benefício do artigo $45 .^{\circ}$ TFUE pode ser invocado não só pelos próprios trabalhadores mas também pelos seus empregadores. Com efeito, para ser eficaz e útil, o direito que os trabalhadores têm de ser contratados e de terem uma ocupação, sem discriminação, deve necessariamente ter como complemento o direito de os empregadores os contratarem, no respeito das regras em matéria de livre circulação dos trabalhadores"

82. A título preliminar, há que recordar que é jurisprudência assente que o artigo $56^{\circ}$ TFUE exige não só a eliminação de qualquer discriminação contra o prestador de serviços estabelecido noutro Estado Membro, em razão da sua nacionalidade, mas também a supressão de qualquer restrição, ainda que indistintamente aplicada aos prestadores nacionais e de outros Estados Membros, quando seja suscetível de impedir, perturbar ou tornar menos atrativas as atividades do prestador estabelecido noutro Estado Membro, onde preste legalmente serviços análogos. Quanto aos trabalhadores migrantes e aos trabalhadores fronteiriços, o facto de terem acedido ao mercado de trabalho de um Estado Membro gera, em princípio, o vínculo de integração suficiente na sociedade 
desse Estado que lhes permite aí beneficiar do princípio da igualdade de tratamento, relativamente aos trabalhadores nacionais, no tocante às vantagens sociais. Este princípio é aplicável não só a todas as condições de trabalho mas também a todas as vantagens que, estando ou não ligadas a um contrato de trabalho, são geralmente reconhecidas aos trabalhadores nacionais em razão, principalmente, da sua qualidade objetiva de trabalhadores ou do simples facto de terem a sua residência habitual no território nacional (v., designadamente, acórdãos de 12 de maio de 1998, Martínez Sala, C 85/96, Colet., p. I 2691, n 25, e Comissão/Alemanha, já referido, n 39). 66 O vínculo de integração resulta, nomeadamente, do facto de o trabalhador migrante também contribuir, com os tributos que paga no Estado Membro de acolhimento devido ao trabalho por conta de outrem que aí presta, para o financiamento das políticas sociais desse Estado, devendo delas beneficiar nas mesmas condições que os trabalhadores nacionais. (UNIÃO EUROPEIA, 2014).

Com isso, partindo-se do pressuposto da livre circulação de trabalhadores, na União Europeia, se estabelecem inúmeras condições para que tal desiderato tenha plena efetividade, dentre eles, a proteção dos Tratados e demais atos e a atuação importante da jurisprudência. Não menos importantes, são os instrumentos administrativos para a concretização desta liberdade, como a Rede EURES. As Convenções da OIT e também, aqui se acrescente, a atuação das empresas, também favorecem a efetivação da livre circulação de trabalhadores na União Europeia.

Sabendo-se que a circulação de trabalhadores na União Europeia é fato corriqueiro, não somente os Estados e a legislação da União, como um todo, devem estar preparados para resolver questões decorrentes de discriminação de trabalhadores migrantes, mas os próprios sujeitos, ou seja: o migrante, o trabalhador nacional e os patrões. Questões como a fraternidade e o reconhecimento são basilares neste sentido, as quais serão abordados no tópico seguinte.

\section{A NÃO DISCRIMINAÇÃO AO TRABALHADOR MIGRANTE NA}




\section{UNIÃO EUROPEIA SOB AS PERSPECTIVAS DA FRATERNIDADE E DO RECONHECIMENTO}

Neste item serão tratados fraternidade e reconhecimento para se estabelecer paradigmas para a mitigação da discriminação no trabalho no que diz respeito à migração de trabalhadores na União Europeia.

A igualdade e a nao discriminação devem ser consideradas segundo uma gama de circustâncias (COIMBRA; ARAUJO, 2014), vez que situações de diferenciações podem nao ter intuito desmerecedor e prejudicial, mas de proteção dos menos favorecidos, a fim de se estabelecer um tratamento mais igual possível entre estes e os demais. Numa dada sociedade, numa certa época, diante de algumas particularidades, é necessário que se estabaleçam parâmetros não somente normativos, mas práticos, políticas redistributivas (COIMBRA; ARAUJO, 2014), mudanças nos relacionamentos interpessoais, no intuito de se manter a paz e contribuir para o desenvolvimento de uma "humanidade" de fato.

Como definido por Habermas, o nacionalismo pode provocar uma tragédia, como fez na Alemanha. Esse nacionalismo determina nas pessoas o pensamento de que, por compartilharem uma história em comum, além da língua e da cultura, são homogêneos e, por isso, assim devem permanecer. Trata-se de discriminação decorrente do excesso de nacionalismo e da não aceitação do diferente como igual, o que pode ser facilmente notado no ambiente de trabalho. (HABERMAS, 2004.)

Por esta razão, sem se esquecer de defender princípios universais (democracia e do respeito pelos direitos humanos), Habermas tenta dissociar Estado e nação com a finalidade de definir um pós-nacional - ou seja, uma identidade. (HABERMAS, 1992) Essa teoria do patriotismo constitucional não é uma abstração. Ela decorre do debate e é, portanto, legitimada por ele. A natureza idealista desta teoria pode ser questionada onde enfatiza a importância do debate como sendo o único meio de identificar os princípios universalistas aceites por todos, e assim de reavaliar suas próprias opiniões. O filósofo entende que a integração dos cidadãos pertencentes a diferentes nações europeias implica a construção de patriotismo constitucional, e no Parecer do Conselho de Europa, isso significa promover a integração dos migrantes no país de acolhimento. (HABERMAS, 1992)

Nessa linha, a existência de princípios cívicos universalistas deve ir além de referências étnicas, linguísticas e culturais e também evitar a exaltação trágica de uma história ou cultura. 
Dentre estes princípios ou valores universais, Amy Gutmann, defende que o reconhecimento intersubjetivo não pode levar em consideração sexo, raça ou procedência étnica, assim como deve haver respeito às "formas de ações, práticas e visões peculiares do mundo que gozam de prestígio junto aos integrantes dos grupos desprivilegiados, ou que estão intimamente ligados a essas pessoas". (GUTMANN, 1994 apud HABERMAS, 2004, p. 240).

O mesmo vale para estrangeiros residentes em outro país, com o fito de não somente fixar residência, mas de trabalhar. Trazendo o pensamento de Gutmann e de Habermas para a realidade da União Europeia, pode-se afirmar que não se trata da exigência de "igualamento de condições sociais de vida", mas da defesa da "integridade das formas de vida e tradições com as quais os membros de grupos discriminados possam identificar-se". (HABERMAS, 2004, p. 240)

Perceptível que Habermas entendeu pela existência de uma forma de não reconhecimento cultural que reflete em discriminação, em "demérito social". (HABERMAS, 2004, p. 240) Para a realidade em análise, pode-se afirmar que a situação do migrante dentro da União Europeia pode, por vezes, configurar-se não somente como de não reconhecimento como cidadão (cidadão da União Europeia), mas também como detentor de direito iguais aos dos trabalhadores do país de acolhida, vindo a sobressair a realidade da discriminação.

Importante ainda que se registre que a não discriminação e o por em prática os direitos da União Europeia aos nacionais dos países membros deve significar a coexistência das pessoas, de forma natural e pacífica, nessa comunidade que tem por objetivo principal a prática das liberdades fundamentais, através da cooperação, da integração e do respeito mútuo. (HABERMAS, 2004)

Os diferentes grupos étnicos e as culturas devem ser observados e respeitados com a finalidade de que, efetivamente, se dê eficácia aos direitos formalmente instituídos, expostos no tópico anterior. Veja-se que Habermas defende que isto não deve pautar-se na normatividade, mas através da "defesa dos contextos vitais e experiências partilhados intersubjetivamente, nos quais a pessoa foi socializada (...) a identidade do indivíduo está entretecida com identidades coletivas e só pode estabilizar-se em uma rede cultural que está longe de poder ser adquirida como propriedade quanto a própria língua materna". (HABERMAS, 2004, p. 257)

Nesse norte, Habermas conduz à conclusão de que é impossível a coexistência equitativa de diferentes grupos étnicos se não se assegurarem a todos direitos que estejam além do individualismo, ou seja, deve ser ultrapassado 
o "isolamento étnico" (HABERMAS, 2004, p. 259) para que se tenha uma verdadeira integração e efetivação dos direitos, no caso, estabelecidos na União Europeia.

Embora num primeiro momento se possa pensar que não, tendo em vista a ampla gama de direitos normatizados, existe ainda discriminação ao estrangeiro, no âmbito da União Europeia. Destarte, não se pode falar numa integração verdadeira senão pelo viés de um "teor ético neutro" na fixação de uma política que unifique, num Estado, as diferenças entre as comunidades étnico-culturais que possuem, cada qual, sua percepção acerca do que é "o bem". (HABERMAS, 2004, p. 265)

Ainda se entende que essa visão ético-política de nação se vê afetada com a migração, o que leva a uma contraposição à autodeterminação, ou seja, se o indivíduo possui liberdade de locomoção da União Europeia e deseja fixar residência em outro país-membro, deveria aglutinar a vida cultural do país receptor, esquecendo-se da de seu país? Do mesmo modo, o povo que recebe, tem o direito de discriminar o indivíduo natural de outro Estado, em nome da manutenção daquilo que entende por "sua nação"? (HABERMAS, 2004)

Com isso, registra-se que na situação de hoje, na qual o anseio por imigração supera enormemente a disposição ao acolhimento, coloca-se a pergunta se, para além da postulação moral de integração, subsiste também um direito legítimo à integração? (HABERMAS, 2004) Pretende-se responder esta pergunta, em seguida.

Nessa linha, a imagem hegeliana do homem se ajusta a essas premissas e é perfeitamente coerente com o sistema que vê a esfera política não como "uma união mecânica" de indivíduos igualmente soberanos, mas como unidade orgânica de classes e funções regidas pelo princípio da universalidade. Paralelamente a isso, toda a vida social é entendida "em sentido orgânico" e não como conjunto de indivíduos indiferenciáveis concebidos abstratamente na uniformidade de sua natureza sensível e racional. (RIDOLA, 2014).

Segundo Rios, a posição de desvantagem de alguns grupos, aqui se tratando dos migrantes dentro da União Europeia, se dá pelas seguintes abordagens: teoria do estigma e teoria da desvantagem dos grupos discriminados. (RIOS, 2008) A segunda poderia se adaptar melhor à situação em análise no presente artigo, tendo em vista que estuda o fato de que os discriminados estão expostos à situação de privações decorrentes das "práticas e instituições sociais que criam, reproduzem e perpetuam desigualdades materiais" (BRAGATO, 2013, p. 80)

Conforme Bragato: 
Quando a modernidade europeia assentou o fundamento da dignidade na racionalidade humana e construiu o conceito de raça e racismo, produziu-se, historicamente, a construção de um padrão de humanidade encarnado na figura do indivíduo masculino, branco, proprietário, ocidental, heterossexual e cristão. Como padrão unitário, superior e cientificamente orientado de comportamento, a racionalidade tornou-se um atributo culturalmente centrado (ou etnocêntrico) e, portanto, ausente em diversos exemplares da espécie humana, como é o caso (...) dos estrangeiros. (BRAGATO, 2013, p. 83)

Supiot, em sua "Crítica ao Direito do Trabalho", informa que a fraternidade possui dois sentidos, um é a legitimação da igualdade e da hierarquia e o outro é fonte de inclusão e de exclusão. Ou seja, pode-se ter a fraternidade como doçura e conciliação, ou como combate e exclusão (aqui se verifica a exclusão daqueles que não são descendentes da mesma origem, ou seja, os estrangeiros - trabalhadores migrantes, neste artigo). (SUPIOT, 1996)

Do ponto de vista positivo, a fraternidade se funda em um sentimento de comunidade, e não em um agrupamento racional. Tem-se, então, um sentimento de pertença a uma sociedade - comunidade, ainda que não na de origem, ou seja, fora de seu país natal o sujeito ainda é considerado detentor de direitos e se vê parte da sociedade do país que o recebe, como trabalhador. (SUPIOT, 1996)

Segundo Câmara, a fraternidade pode sim ser vista como um "princípio inspirador", através do qual se universalizam os direitos, importando em um "norte interpretativo", ou seja, pode vir a constituir-se em um "conceito operacional, sob a ótica do jurista". (CÂMARA, 2012, p. 85) Veja-se isto no artigo $1^{\circ}$ da Declaração Universal dos Direitos Humanos (1948): “todas as pessoas nascem livres e iguais em dignidade e direitos. São dotadas de razão e consciência e devem agir em relação umas às outras com espírito de fraternidade".

Cançado, também neste sentido, clama pela

(...) necessidade de todos os cidadãos exercitarem a fraternidade, inclusive no campo do direito, adotando-a como princípio norteador (...), se realmente se quiser diminuir os conflitos sociais trabalhistas e tornar efetivo o veto à violação 
da dignidade do homem, à sua utilização como mero objeto a serviço de outrem. (CANÇADO, 2009, p. 128)

Segundo Habermas, o que confirma os dados estatísticos mencionados no tópico anterior, desde o crescimento explosivo da imigração (e migração) em todo o mundo, no século XIX, grande parte das pessoas que procuram outros Estados para residir é formada por trabalhadores em busca de melhor qualidade de vida. (HABERMAS, 2004)

Esse maciço movimento, especialmente o que se desenha na União Europeia, de trabalhadores de países menos favorecidos para países mais desenvolvidos, gera em ampla gama da população de trabalhadores do país de recepção um sentimento de precaução, isto é, de abrirem-se os olhos para o "diferente", buscando "defender" seus direitos em detrimento do trabalhador migrante. Como se o migrante não tivesse direitos, a sociedade se fecha para ele, a vizinhança não o acolhe, os colegas de trabalho o excluem e, mansamente, se estabelece a discriminação, fortemente baseada agrupamento racional (conforme entendimento de Supiot, acima registrado) que hoje já deveria ter sido ultrapassado, diante da rapidez com a qual a sociedade se modifica e com a qual o direito deve saber pautar-se. (SUPIOT, 1996)

Conforme Honneth, o outro deixa de ser reconhecido porque a) há convicção, preconceito ou estereótipo que o negam, ou porque b) o sujeito que nega está imerso numa concepção de que o outro é visto como objeto. A adesão à primeira hipótese impede o reconhecimento do outro como sujeito de direitos, como no caso da xenofobia, da discriminação do migrante, dentro do âmbito da União Europeia. (HONNETH, 2007)

A corroborar, cita-se novamente a Convenção 111 da OIT, a qual trata dos tipos diretos de discriminação, dentre os quais se podem destacar, pela ligação com o presente artigo, os decorrentes de ascendência nacional, de raça e de religião. O primeiro diz com o fato de que o estrangeiro, diferente do ponto de vista cultural, não deve sofrer discriminação no ambiente de trabalho. Quanto às questões de raça e de religião, o mesmo se aplica, pois os trabalhadores migrantes não podem ser discriminados pela sua origem étnica ou pela religião que professam. (BARZOTTO, 2012)

Bragato traz à baila situação prática de discriminação vivenciada pelas mulheres que professam a religião muçulmana, na França, vez que foi editada uma lei pela qual se proibiu o uso de véu - ou melhor, cobrir o rosto, em locais públicos. Veja-se que a lei não se mostra de caráter geral, porquanto se dirige 
às mulheres que usam véu. Assim, a trabalhadora migrante de país da União Europeia, muçulmana, quando ingressar na França, para exercer seu trabalho, não poderá usar véu em locais públicos, sendo, em última análise, discriminada no país de acolhimento, no caso, a França. (BRAGATO, 2013)

Assim, dentro do contexto de acolhimento, conforme Habermas, se entende haver uma "postulação moral" de integração, assim como um "direito legítimo à integração", respondendo-se ao questionamento feito pelo próprio autor, registrado anteriormente. (HABERMAS, 2004, p. 268)

Dentro desta perspectiva de afastamento do trabalhador migrante dos demais trabalhadores do país de recepção, dentro da União Europeia, se visualiza a questão do "reconhecimento" de Hegel, defendida por outros filósofos, e amplamente estudada por Axel Honneth. Ou seja, há necessidade de que entre os trabalhadores de origem e os migrantes se estabeleça um "reconhecimento recíproco", "porque os sujeitos só podem chegar a uma autorrelação prática quando aprendem a conceber, da perspectiva normativa de seus parceiros de interação, como seus destinatários sociais”. (HONNETH, 2003, p. 155)

Neste contexto, tem-se a efetividade das normas da União Europeia quanto a não discriminação, a fim de que se estabeleça uma "coerção normativa" obrigando os sujeitos ao reconhecimento recíproco, a fim de que as "pretensões de sua subjetividade" possam obter uma expressão social. (HONNETH, 2003, p. 155-156)

Conforme Morin:

Em nosso mundo de homens [...] mais do que sonhar com a harmonia geral ou com o paraíso, devemos reconhecer a necessidade vital, social e ética de amizade, de afeição e de amor pelos seres humanos, os quais, sem isso, viveriam de hostilidade e de agressividade, tornando-se amargos ou perecendo. (MORIN, 2007, p. 36)

Envoltos em legislação vasta e bastante protetiva, num primeiro momento, poder-se-ia pensar numa situação ideal para os trabalhadores, no seio da União Europeia, como referido. Entretanto, como em todo sistema social, há atritos, divergências, diferenças e problemas à espera de solução. Situação não diferente a esta se apresenta na União Europeia, porquanto o ser humano não se vislumbra completo sem as vestes da "utilidade". Ou seja, ciente de que possui um papel na sociedade, um trabalho, um emprego, uma família, sente-se 
senhor de si e não somente sabe que possui direitos, mas exige que os mesmos sejam observados.

No caso da livre circulação de trabalhadores, devidamente assegurada pela legislação da União Europeia, observa-se, em concreto, o que entendeu François Ost a respeito da terceira figura de desinstituição social (o trabalho), em sua obra "O tempo do Direito", no sentido de que:

Reconhecido, o trabalhador passa a ser sujeito de direito, portador de um estatuto, geral e abstrato, que o inscreve num coletivo cujo lugar social está consagrado. Sob a égide da lei e da sua ordem protetora o trabalhador pode doravante circular num território abstrato e jurídico que o liberta das limitações pessoais e das sujeições locais, dando-lhe dignidade, utilidade e acesso ao espaço público. (OST, 2001, p. 23)

Conforme Ridola, o homem "não age mais numa esfera de liberdade relativa, num espaço reservado, dado por seu Criador, e com limites preestabelecidos. Assim, a perspectiva da imago Dei começa a ser substancialmente superada por uma visão do homem que, precisamente porque feito à imagem de seu criador, é também 'senhor' de seu mundo". (RIDOLA, 2014, p. 33)

Na perspectiva de Hannah Arendt, "o animal laborans é apenas uma das espécies animais que vive na terra - na melhor das hipóteses, a mais desenvolvida". (ARENDT, 2001, p. 95)

Quanto à este tema, Lefebvre et. al. informam que "na dependência e na reciprocidade do trabalho e da satisfação das carências, a necessidade subjetiva transforma-se numa contribuição para a satisfação das carências de todos os outros". (LEFEBVRE; MACHEREY, 1999, p. 42)

No mesmo sentido, como aduz Reis, "o trabalho, que na face biológica é cíclico, rotativo e recorrente - passa a propulsionar um movimento em espiral, que tem por vetor a consciência da liberdade”. (REIS, 2012, p. 15-33)

Acerca das fontes do direito, no âmbito do Direito do Trabalho na União Europeia, diante não somente da comunidade como da globalização, tem-se o entendimento de Peduzzi, no sentido de que:

Ao enfraquecimento do direito nacional corresponde, por conseguinte, o robustecimento da atividade de criação do 
direito na esfera infra-estatal (corporações, particulares, onde se inserem as convenções e os acordos coletivos de trabalho) e no contexto transnacional (organismos internacionais, blocos econômicos). Trata-se de uma situação particular e inédita de pluralismo jurídico. (PEDUZZI, 2003, p. 21).

Conforme Reis (2012), os instrumentos internacionais de defesa dos direitos dos trabalhadores têm importância crucial para favorecer as distorções da proteção do direito nacional frente à globalização.

Com isso, importante que se institua a discussão a respeito das questões subjetivas que emergem dos direitos estabelecidos, com a finalidade de que sejam efetivos, ou seja, sem se ter em mente as implicações que o direito estabelece nas vidas dos indivíduos, não há possibilidade de fazê-lo efetivo.

Dessa forma, estabelecendo-se que os direitos à liberdade de circulação e a não discriminação, devidamente positivados, devem ser internalizados pelos indivíduos da União Europeia, entende-se que possam ser mais facilmente postos em prática e respeitados. E, para isso, a fraternidade e o reconhecimento se mostram bastante significativos, porém, sempre devem ser exercitados.

\section{CONCLUSÃO}

Em que pese, no âmbito da União Europeia, haja legislação buscando a efetivação dos direitos à livre circulação de trabalhadores e a não discriminação a realidade social diverge da letra da lei e das intenções dos governos e de outras instituições que têm por objetivo a defesa dos trabalhadores, pois a globalização e o multiculturalismo exigem posturas ainda mais atuantes e ativas para a proteção e a efetivação dos direitos.

A xenofobia, o preconceito e a discriminação são situações que não se eliminam pura e simplesmente pela imposição normativa. Diversamente, esta imposição é parte do processo de efetivação de direitos, que ainda passa pela recepção interna dos indivíduos a este respeito, sejam nacionais ou não, conforme o aparato filosófico a respeito da fraternidade e do reconhecimento utilizado neste ensaio.

Assim, tem-se por extremamente válido o estudo a respeito das implicações subjetivas quanto se trata de Direito do Trabalho, tendo em vista que a pessoa do trabalhador, o animal laborans, na expressão de Arendt, é 
extremamente delicado do ponto de vista de sua individualidade, porquanto o trabalho não possui meramente o sentido de sustento, mas de afirmação social do ser humano.

Daí a necessidade de se pensar a problemática da efetividade dos direitos trabalhistas formalmente estabelecidos na União Europeia a partir da fraternidade e do reconhecimento das relações de trabalho no âmbito do Bloco, especialmente no que diz respeito ao trabalhador migrante.

\section{REFERÊNCIAS}

ARENDT, Hannah. A condição humana. Rio de Janeiro: Forense Universitária, 2001.

BARROS, Caio Mesquita. Direito comunitário: aspectos trabalhistas. In: Fundamentos do direito do trabalho. São Paulo: LTr, 2000.

BARZOTTO, Luciane Cardoso. Igualdade e discriminação no ambiente de trabalho. In: Trabalho e igualdade: tipos de discriminação no ambiente de trabalho. Coord. Luciana Cardoso Barzotto. Porto Alegre: Livraria do Advogado, 2012, p. 35-53.

BRAGATO, Fernanda Frizzo. Direitos humanos além da lógica formal do princípio da igualdade: uma leitura a partir do princípio da nãodiscriminação. In: Constituição, sistemas sociais e hermenêutica. Porto Alegre: Livraria do Advogado, 2013, p. 77-91.

CÂMARA, Sílvia Beatriz Gonçalves. A concretização da fraternidade e as relações de trabalho: uma abordagem acerca da discriminação e exclusão social. In: Trabalho e Igualdade : tipos de discriminação no ambiente de trabalho. Coord. Luciana Cardoso Barzotto. Porto Alegre: Livraria do Advogado, 2012, p. 81-91.

\section{CAMPANA, Fabio. Cresce violência contra imigrantes na Europa.}

Disponível em: $<$ http://www.fabiocampana.com.br/2009/02/violenciacontra-imigrantes-cresce-na-europa-em-razao-da-crise-economica/)> . Acesso em: 15 ago. 2014. 
CANÇADO, Andrea Aparecida Lopes. O contrato de trabalho no século XXI e o esquecido princípio da fraternidade. Revista do Tribunal da $3^{\mathbf{a}}$ Região. Belo Horizonte: Sigma, v. 49, n. 79, 2009.

COIMBRA, Rodrigo; ARAÚJO, Francisco Rossal de. Direito do trabalho I. São Paulo: LTr, 2014.

EURES. O que pode a EURES fazer por si? 2015, p.1. Disponível em : https://ec.europa.eu/eures/public/pt/what-can-eures-do-for-you-. Acesso em: 30 ago. 2015.

EUROBAROMETER. Disponível em: <http://ec.europa.eu/>. Acesso em: 30 ago. 2014.

EUROSTAT. Disponível em <http://epp.eurostat.ec.europa.eu>. Acesso em: 25 ago. 2014.

GUTMANN, A. (Ed. ). Examining the Politics of Recognition. In: HABERMAS, Jürgen. A inclusão do outro: estudos de teoria política. Tradução George Sperber e Paulo Astor Soethe. São Paulo: Loyola, 2004.

HABERMAS, Jürgen. Direito e democracia: entre facticidade e validade. Rio de Janeiro: Tempo Brasileiro, 1992. t.I e II.

HABERMAS Jürgen. (1992): Citizenship and national identity: some reflexions on the future of Europe. Praxis International, n.12, 1992.

HEGEL, Georg Wilhelm Friedrich. Fenomenologia do espírito. Tradução de Paulo Meneses, com colaboração de Karl-Heinz Efken. 6 ed. Petrópolis: Vozes, 2001. pt. I.

HONNETH, Axel. Luta por reconhecimento: a gramática social dos conflitos morais. Tradução Luiz Repa. São Paulo: Editora 34, 2003.

HONNETH, Axel. Reificación: un estudio en la teoria del reconocimiento. Buenos Aires: Katz Editores, 2007. 
INSTITUTO BRASILEIRO DE GEOGRAFIA E ESTATÍSTICA.

Disponível em < http://www.ibge.gov.br/home/>. Acesso em 30, ago./2014.

LEFEBVRE, Jean-Pierre; MACHEREY, Pierre. Hegel e a Sociedade.

Tradução Thereza Christina Ferreira Stummer e Lygia Araújo Watanabe. São Paulo: Discurso Editorial, 1999.

MELGAR, Alfredo Montoya; MORENO, Jesús M. Galiana; NAVARRO, Antonio V. Sempere. Derecho social europeo, Madrid: Tecnos, 1994.

OFFICE OF THE UNITED NATIONS HIGH COMMISSIONER FOR HUMAN RIGHTS. Disponível em: $<$ http://www.ohchr.org/SP/ ProfessionalInterest/Pages/CMW.aspx)>. Acesso em: 22 ago. 2014.

ORGANIZAÇÃO DAS NAÇÕES UNIDAS. Disponível em $<$ http:// nacoesunidas.org/>. Acesso em: 23 ago. 2014.

ORGANIZAÇÃO INTERNACIONAL DO TRABALHO. Convenções. Disponível em: <http://www.ilo.org>. Acesso em: 25 ago. 2014.

OST, Françoise. O tempo do Direito. São Paulo: Piaget, 2001.

MORIN, Edgar. O método: ética. 3 ed. Porto Alegre: Meridional, 2007. v.6.

PALOMEQUE LÓPEZ, Manuel Carlos; DE LA ROSA, Manuel Álvarez. Derecho del trabajo. 9.ed. Madrid: Editorial Universitária Ramon Areces, 2001.

PEDUZZI, Maria Cristina Irigoyen. Globalização, integração de mercados e repercussões sociais: perspectivas do Direito do Trabalho no Brasil. In: Revista do Tribunal Superior do Trabalho. São Paulo: Lex Magister, v. 69, n. 1, p. 21-39, jan./jun. 2003.

POCAR, Fausto, Derecho comunitario del trabajo. Trad. José Henrique Serrano Martinez. Madrid: Civitas, 1988. 
REIS, Daniela Murad. Discriminação nas relações de trabalho e emprego: reflexões éticas sobre o trabalho, pertença, exclusão social e os instrumentos jurídicos de retificação. In: Trabalho e igualdade: tipos de discriminação no ambiente de trabalho. Porto Alegre: Livraria do Advogado, 2012. p. 15-33.

\section{RIDOLA, Paola. A dignidade humana e o "princípio liberdade" na} cultura constitucional europeia. Tradução Carlos Luiz Strapazzon e Tula Wesendonck. Coord. Ingo Wolfgang Sarlet. Porto Alegre, Livraria do Advogado, 2014.

RIOS, Roger Raupp. Direito da antidiscriminação: discriminação direta, indireta e ações afirmativas. Porto Alegre: Livraria do Advogado, 2008.

\section{SANCHO, Angel; CHUECA, G.. Los derechos fundamentales en la} comunidad europea. Barcelona: Casa Editorial Bosch, 1989.

SHELTON, Dinah. Prohibición de discriminación em el derecho internacioal de los derechos humanos. In: Anuario de derechos humanos. n 4, 2008. Disponível em: $<$ http://www.anuariocdh.uchile.cl/index.php/ADH/article/ viewFile/13488/137560>. Acesso em: 25 ago. 2014.

SUPIOT, Alain. Crítica del derecho del trabajo. Tradução José Luis Gil y Gil. Espanha: Ministerio de Trabajo y Asuntos Sociales, Subdirección General de Publicaciones, 1996.

UNIÃO EUROPÉIA. TRIBUNAL DE JUSTIÇA. Jurisprudência. 2014. Disponível em: $<$ http://curia.europa.eu/juris/document/document. jsf?text=estrangeiro $\% 2 \mathrm{Bdiscrimina} \% 25 \mathrm{C} 3 \% 25 \mathrm{~A} 7 \% 25 \mathrm{C} 3 \% 25 \mathrm{~A} 3 \mathrm{o} \%$ 2Btrabalho\%2B\&docid $=151973 \&$ pageIndex $=0 \&$ docl ang $=$ PT \&mode $=$ req \&dir $=\&$ occ $=$ first $\&$ part $=1 \&$ cid $=453252 \#$ Footref30 $>$. Acesso em: 30 ago. 2014.

Disponível em: . Jurisprudência. 2014.

http://curia.europa.eu/juris/document/document.jsf? text=estrangeiro $\% 2 \mathrm{Bdiscrimina} \% 25 \mathrm{C} 3 \% 25 \mathrm{~A} 7 \% 25 \mathrm{C} 3 \% 25 \mathrm{~A} 3 \mathrm{o} \% 2 \mathrm{Btrabalho}$ $\% 2 \mathrm{~B} \&$ docid $=123844 \&$ pageIndex $=0 \&$ doclang 
$=$ PT\&mode $=$ req $\&$ dir $=\&$ occ $=$ first $\&$ part $=1 \&$ cid $=453252 \#$ ctx $1>$. Acesso em:

30 ago. 2014.

. Legislação. 2014. Disponível

em: <http://eur-lex.europa.eu/LexUriServ/>. Acesso em: 30 ago. 2014.

Como citar: COIMBRA, Rodrigo; WITTCKIND, Ellara Valentini. A livre circulação de trabalhadores e a não discriminação ao migrante na União Europeia: digressões acerca da fraternidade e do reconhecimento nas relações de trabalho. Scientia Iuris, Londrina, v. 20, n. 1, p. 194-219, abr. 2016. DOI: 10.5433/2178-8189.2016v20n1p194. ISSN: $2178-8189$.

Submetido em $24 / 02 / 2015$

Aprovado em 02/10/2015 